\title{
LÍQUIDO SINOVIAL DE EQÜINOS: PROTEÍNA, CELULARIDADE E PRECIPITAÇÃO DE MUCINA, A FRESCO, APÓS REFRIGERAÇÃO E CONGELAMENTO
}

\author{
SYNOVIAL EQUINE FLUID: PROTEIN, CELLULARITY AND MUCIN CLOT, \\ ON FRESH, AFTER COOLING AND FREEZING
}

\author{
Fabiola de Oliveira Paes Leme ${ }^{1}$ Geraldo Eleno Silveira Alves ${ }^{2}$ Antônio de Pinho Marques Júnior ${ }^{3}$ \\ Ivan Barbosa Machado Sampaio ${ }^{4}$ Jorge José Rio Tinto de Matos ${ }^{5}$
}

\section{RESUMO}

\begin{abstract}
Considerando que as patologias que determinam claudicação são comuns e representam um importante aspecto na Medicina Veterinária Eqüina, com cerca de 33\% das claudicações devendo-se a enfermidades articulares, o presente trabalho teve por objetivo comparar o líquido sinovial de eqüinos a fresco, após refrigeração e após congelamento, para avaliar sua estabilidade e possível utilização como terapêutica. Foram utilizados 25 animais dos quais foram obtidos, por artrocentese, $5 \mathrm{ml}$ de líquido sinovial de ambas as articulações intertársicas proximais. As amostras de cada animal foram misturadas e a amostra final foi dividida em três alíquotas, sendo então analisadas a fresco (GI), após refrigeração (GII) e após congelamento (GIII). A proteína foi significativamente diferente entre os grupos I e II, e II e III ( $p<0,05)$; todavia, nos grupos I e III foi equivalente ( $p>0,05)$. Os grupos I e II, e I e III foram significativamente diferentes $(p<0,05)$ quanto à contagem de leucócitos, enquanto os grupos II e III foram equivalentes $(p>0,05)$. O linfócito foi a célula de predomínio. Alterações morfológicas foram observadas em $8 \%$ dos leucócitos em animais do Grupo II e em 64\% em animais do GIII. Os três grupos estudados foram equivalentes quanto à precipitação de mucina $(p>0,05)$. Com base nos resultados, pode-se concluir que o líquido sinovial sofre alterações quanto à proteína e celularidade após refrigeração e congelamento, porém ainda permanece dentro dos parâmetros aceitáveis de normalidade.
\end{abstract}

Palavras-chave: eqüino, líquido sinovial, proteína, celularidade, тисіпа.

\section{SUMMARY}

Lameness related to arthropathies are common and so very important to Equine Veterinary Medicine, considering that almost 33\% of all lamenesses are due to arthropathies. The present experiment aimed the evaluation of synovial fluid estability after cooling and freezing and its possible therapeutical utilization. Samples of synovial fluid were taken from 25 equines, from both intertarsus proximall joints by arthrocentesis. Samples from each animal were mixed and then divided into 3 aliquotes, and analysed fresh (GI), after cooling (GII) and after freezing (GIII). The protein evaluation showed significant difference between GI and GII and II and III, but GI and GIII were statistically similar. Leukocytes counting showed GI and GII, and GI and GIII to be statistically different, but no difference was seen between GII and GIII. Lymphocyte was the predominant cell in $96 \%$ of the cases. Morphological abnormalities in $8 \%$ of the leukocytes of animals in GII and in 64\% of those in GIII were found. Mucin clot showed no difference betwen all groups studied. Based on the results, it was possible to conclude that the synovial fluid has different protein and cellularity values after cooling and freezing, but is still in the normal range.

Key words: equine, synovial fluid, protein, cellularity, mucin clot.

\section{INTRODUÇÃO}

A claudicação representa um aspecto importante na Medicina Veterinária Eqüina e cerca de $33 \%$ das claudicações devem-se a enfermidades ar-

\footnotetext{
${ }^{1}$ Médico Veterinário, Pós-graduando, Escola de Veterinária da Universidade Federal de Minas Gerais (UFMG). Rua Alagoas, 896/1101, 30130-160 Belo Horizonte, MG. E-mail: fabivet@dedalus.lcc.ufmg.br. Autor para correspondência

${ }^{2}$ Professor Adjunto, Doutor, Escola de Veterinária, UFMG.

${ }^{3}$ Professor Titular, PhD., Escola de Veterinária, UFMG.

${ }^{4}$ Professor Ttitular, Doutor, Escola de Veterinária, UFMG.

${ }^{5}$ Professor Auxiliar III, Departamento de Veterinária da Universidade Federal de Viçosa, Viçosa-MG. Recebido para publicação em 18.05.98. Aprovado em 06.08.98
} 
ticulares (MENDE, 1988). Diagnóstico precoce e tratamento apropriados influenciam significativamente o prognóstico dessas enfermidades (STONEHAM, 1997).

O líquido sinovial de uma articulação normal é um dialisado do plasma modificado pela produção de ácido hialurônico, glicoproteínas e outras macromoléculas. Entretanto, a glicose e alguns eletrólitos também podem estar presentes no líquido sinovial, em concentrações similares às do plasma. As proteínas do plasma atravessam a barreira hematosinovial em quantidades inversamente proporcionais ao seu peso molecular (CLYNE, 1987) e seus valores normais estão entre 0,92 a 3,11g/dl (MAHAFFEY, 1992).

O líquido sinovial possui basicamente as funções de nutrir a cartilagem articular e lubrificar as superfícies articulares, minimizando o atrito natural entre cartilagens opostas (CLYNE, 1987). A articulação diartrodial de eqüinos tem sido descrita como uma unidade auto-sustentável, com integridade estrutural e funcional dependente das propriedades físico-químicas da cartilagem, do líquido sinovial, do suporte subcondral adequado e da estabilidade conferida pela fáscia, ligamentos e músculos, necessária para assegurar movimentos associados ao uso da cartilagem. Substâncias como as proteinases são produzidas pela cartilagem articular e líquido sinovial dentro dessa unidade funcional (SPIERS et al., 1994).

YANCIK et al. (1987) utilizaram a análise do líquido sinovial, o exame radiográfico e a artroscopia para a avaliação de enfermidades articulares, mesmo considerando que os dois primeiros exames não possibilitem a determinação precoce da enfermidade articular, e o terceiro necessite de anestesia prévia do paciente. Também a artrocentese percutânea é uma importante técnica para diagnóstico e tratamento de enfermidades articulares em eqüinos, no entanto, a contaminação hemorrágica do líquido sinovial é freqüente (MISHEFF \& STOVER, 1991).

O tratamento das enfermidades articulares pode representar um desafio ao médico veterinário, uma vez que várias condutas terapêuticas têm sido empregadas, porém com resultados discutíveis. A administração intra-articular de dimetilsulfóxido (DMSO) tem demonstrado bons resultados antiinflamatórios, reduzindo os radicais livres e a produção de prostaglandinas na articulação lesada, sem causar efeitos adversos (WELCH et al., 1989). Entretanto, lesões articulares sépticas requerem tratamento rápido com antibioticoterapia sistêmica (STONEHAM, 1997).

A administração de antiinflamatórios esteróides, intra-articular, é efetiva na supressão da inflamação, todavia pode causar redução na produção de proteoglicanos e na síntese de colágeno, além de causar alterações morfológicas (GIBSON et al., 1996). A persistência da inflamação na membrana sinovial determina importantes alterações no líquido sinovial, interrompendo a nutrição articular para agir como barreira para a reabsorção de fluidos, o que caracteriza um ciclo vicioso (MENDE, 1988).

O alotransplante de líquido sinovial foi estudado por MENDE (1988) em animais com artropatias inflamatórias e não-inflamatórias. Nesse estudo, a substituição de parte do líquido sinovial alterado por líquido sinovial normal teve efeito benéfico em todos os casos, uma vez que o próprio líquido sinovial interrompe o ciclo vicioso que pode ocorrer na osteoartrite, normalizando a membrana sinovial. $\mathrm{O}$ transplante de líquido sinovial, por se tratar de um tratamento menos deletério e econômico, pode ser indicado como método terapêutico alternativo, adjuvante no tratamento de enfermidades articulares (MENDE, 1988).

O objetivo deste trabalho foi avaliar e comparar amostras de líquido sinovial de eqüinos antes e depois da conservação sob refrigeração e congelamento, para conhecer sua estabilidade e sua viabilidade para transplante posterior.

\section{MATERIAL E MÉTODOS}

Foram utilizadas 25 fêmeas eqüinas, sem raça definida, entre 2 e 18 anos de idade, sem alterações clínicas aparentes, criadas a campo e provenientes dos municípios de Sete Lagoas (13), Belo Horizonte (2) e Pedro Leopoldo (10). Cada animal foi identificado numericamente de 1 a 25 . O líquido sinovial foi obtido por artrocentese de ambas as articulações intertársicas proximais, na sua face medial, segundo técnica descrita por STASHAK (1987), utilizando-se agulha hipodérmica $25 \times 8$ e seringa de $5 \mathrm{ml}$ descartáveis. As amostras foram homogeneizadas, formando uma única amostra por animal. Em seguida cada amostra foi dividida em três alíquotas. Cada alíquota foi separada em duas partes, com uma delas contendo anticoagulante EDTA sódico a 10\%, na proporção de 1:50 de líquido sinovial.

As alíquotas foram transportadas em recipiente isolante térmico. Uma das alíquotas de cada animal foi analisada entre uma a três horas após a colheita (Grupo I = GI), outra foi refrigerada por 12 a 15 horas, a uma temperatura entre 4 e $8{ }^{\circ} \mathrm{C}$, sendo analisada após esse período (Grupo II = GII), enquanto a terceira alíquota foi congelada (congelamento rápido em freezer) por 24 a 27 horas, sendo posteriormente mantida a temperatura ambiente por 5 a 10 minutos, para descongelamento e subseqüente análise.

As amostras foram processadas e analisadas segundo técnicas descritas por MAHAFFEY (1992), 
nas quais as proteínas foram determinadas por refratometria e a contagem celular realizada em hemacitômetro. A citologia foi analisada em esfregaços do líquido sinovial obtidos do sedimento após centrifugação e corados pelo método panótico de rotina (Figura 1). Os coágulos de mucina foram classificados em: "muito deficiente", "deficiente", "regular" e "bom", em ordem crescente de qualidade (Figura 2).

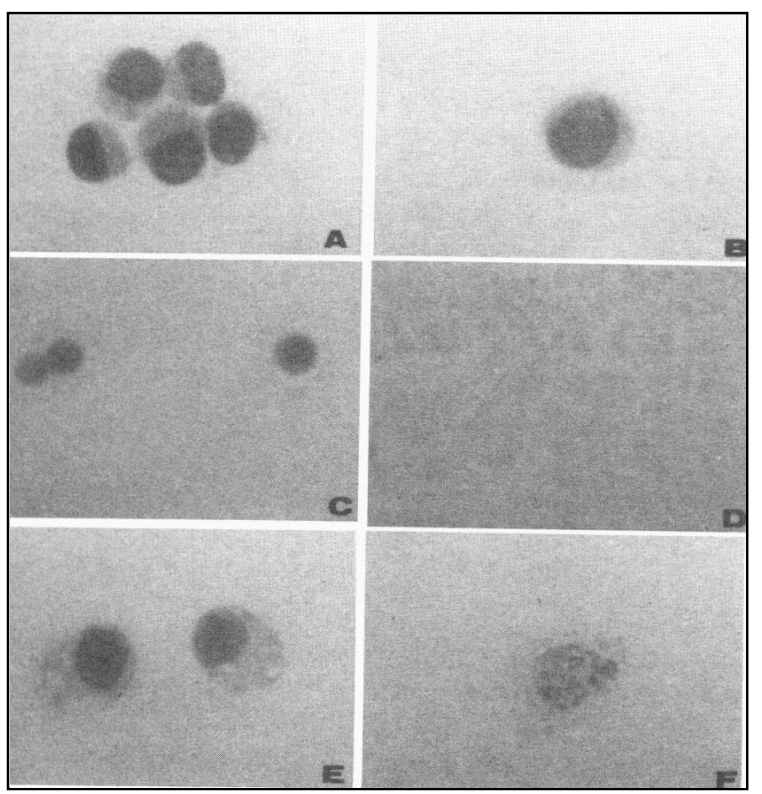

Figura 1 - Esfregaço do sedimento de líquido sinovial de eqüinos corado por panótico (x312)

A - Aglomerado de linfócitos.

B - Linfócito isolado.

C - Eritrócitos circundados por mucina.

D - Mucina.

E - Vacúolos citoplasmáticos e perda de integridade de membrana citoplasmática, observados nos dois linfócitos, após a refrigeração do líquido sinovial por 12 a 15 horas.

F - Pleomorfismo nuclear e citoplasmático, e degeneração celular observados em células do líquido sinovial de eqüinos, após congelamento.

\section{RESULTADOS E DISCUSSÃO}

Os resultados encontram-se nas Tabelas $1 \mathrm{e}$ 2. Os dados da proteína e celularidade foram analisados pelo teste t de Student para dados pareados, enquanto os resultados da precipitação de mucina foram analisados pelo teste estatístico não paramétrico de Kruskal Wallis (ARMITAGE, 1971).

A análise da proteína revelou diferença significativa $(p<0,05)$ entre os grupos GI e GII, e GII e GIII; entretanto, os grupos GI e GIII se mostraram

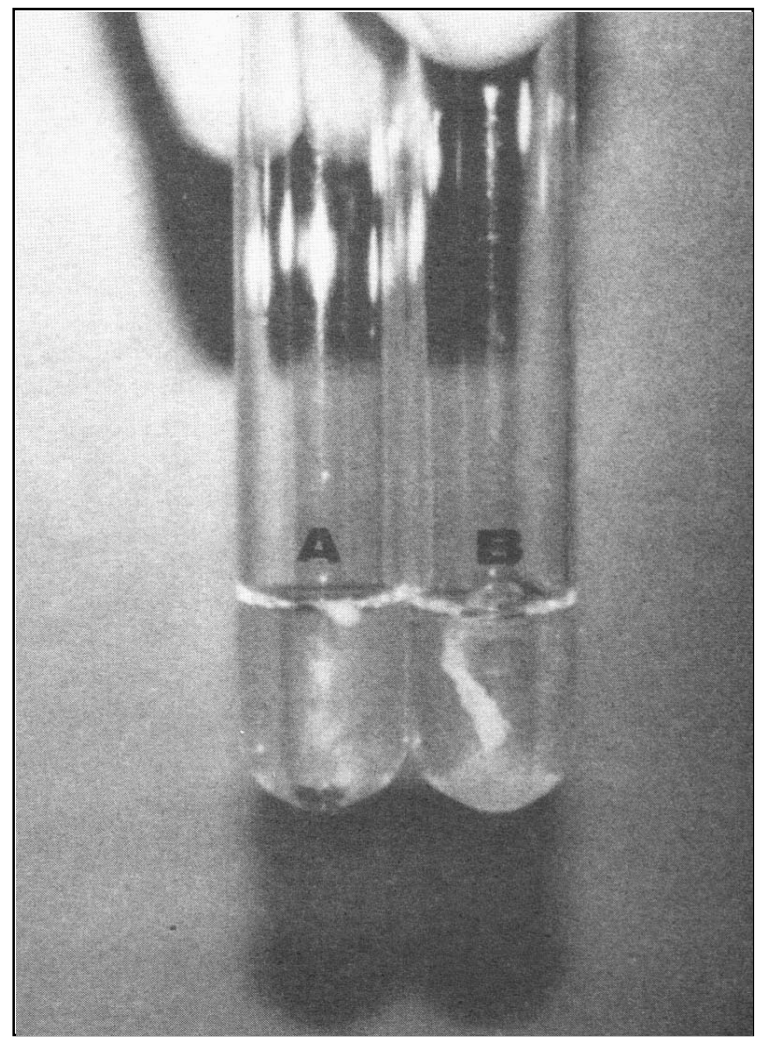

Figura 2 - Coágulos de mucina: (A) “deficiente”, (B) "bom”.

estatisticamente equivalentes ( $p>0,05)$. Observou-se um acréscimo no valor das proteínas do GII, o que pode estar relacionado com o tempo prolongado de contato entre a amostra e o anticoagulante utilizado. $\mathrm{O}$ mesmo não foi observado em GIII, provavelmente devido à estabilidade protéica proporcionada pelo congelamento. Os resultados obtidos nos três grupos analisados encontram-se dentro dos valores de normalidade ( 0,92 a 3,11g/dl), citados por MAHAFFEY (1992).

Os grupos GI e GII, e GI e GIII apresentaram contagens totais de leucócitos significativamente diferentes $(\mathrm{p}<0,05)$, o que se justifica, uma vez que as células, de um modo geral, após conservação, tenderam à fragilidade e à ruptura citoplasmática com o passar do tempo. A análise entre os grupos GII e GIII demonstrou equivalência estatística $(\mathrm{p}>0,05)$.

Os resultados da contagem total de leucócitos encontraram-se dentro dos parâmetros de normalidade (menos de 500 células / $\mu \mathrm{l}$ ) citados por DUNCAN \& PRASSE (1986), para o líquido sinovial de eqüinos. É sabido que células nucleadas são responsáveis pela produção de substâncias importantes ao equilíbrio fisiológico do líquido sinovial e, 
Tabela 1 - Valores da contagem total de hemácias e leucócitos, dosagem de proteína e teste de precipitação de mucina em líquido sinovial de eqüinos analisados a fresco (GI), após refrigeração (GII) e congelamento(GIII).

\begin{tabular}{|c|c|c|c|c|c|c|c|c|c|c|c|c|}
\hline \multirow[t]{2}{*}{ Animais } & \multicolumn{3}{|c|}{ Hemácias $\left(/ \mathrm{mm}^{3}\right)$} & \multicolumn{3}{|c|}{ Leucócitos (/mm3) } & \multicolumn{3}{|c|}{ Proteína (g/dl) } & \multicolumn{3}{|c|}{ Mucina (score 1 a 4 )* } \\
\hline & GI & GII & GII & GI & GII & GIII & GI & GII & GIII & GI & GII & GIII \\
\hline 1 & 2080 & 2720 & 13 & 15 & - & - & 2,8 & 2,8 & 2,6 & 4 & 4 & 4 \\
\hline 2 & 2720 & 1600 & 8 & 5 & - & - & 2,8 & 3,0 & 2,6 & 4 & 4 & 4 \\
\hline 3 & 2720 & 2240 & 53 & 20 & - & - & 3,0 & 3,0 & 3,0 & 3 & 4 & 3 \\
\hline 4 & 2880 & 70 & 10 & 5 & - & - & 2,2 & 2,4 & 2,0 & 4 & 3 & 3 \\
\hline 5 & 250 & 65 & 15 & 10 & 3 & - & 2,4 & 2,6 & 2,4 & 4 & 4 & 4 \\
\hline 6 & 240 & 200 & 10 & 10 & - & - & 2,0 & 2,2 & 2,0 & 4 & 4 & 4 \\
\hline 7 & 5440 & 2880 & 8 & 22 & 3 & - & 2,0 & 2,0 & 2,0 & 4 & 4 & 4 \\
\hline 8 & 1440 & 200 & 13 & 10 & 3 & - & 2,2 & 2,4 & 2,4 & 4 & 4 & 4 \\
\hline 9 & 2240 & 740 & 5 & 8 & - & - & 2,4 & 2,4 & 2,4 & 4 & 4 & 4 \\
\hline 10 & 610 & 510 & 88 & 10 & - & - & 2,0 & 2,2 & 2,0 & 4 & 4 & 4 \\
\hline 11 & 1120 & 960 & 38 & 25 & - & - & 1,8 & 1,8 & 1,8 & 4 & 4 & 4 \\
\hline 12 & 5440 & 2240 & 18 & 20 & - & - & 2,6 & 2,8 & 2,6 & 4 & 4 & 4 \\
\hline 13 & 3520 & 110 & 15 & 5 & - & - & 3,0 & 3,0 & 2,8 & 3 & 2 & 1 \\
\hline 14 & 905 & 525 & 35 & 85 & 25 & 30 & 2,2 & 2,0 & 2,2 & 4 & 4 & 4 \\
\hline 15 & 415 & 335 & 30 & 30 & 20 & 10 & 2,2 & 2,2 & 2,0 & 4 & 4 & 4 \\
\hline 16 & 2000 & 1250 & 5 & 50 & 15 & 10 & 2,0 & 2,0 & 1,8 & 3 & 2 & 2 \\
\hline 17 & 265 & 155 & 15 & 40 & 10 & 10 & 2,4 & 2,2 & 2,4 & 4 & 4 & 4 \\
\hline 18 & 3185 & 2380 & 375 & 350 & 225 & 10 & 2,4 & 2.4 & 2,4 & 4 & 4 & 3 \\
\hline 19 & 2175 & 1830 & 20 & 25 & 40 & 20 & 3.0 & 3,2 & 3,0 & 4 & 4 & 4 \\
\hline 20 & 60 & 50 & 10 & 25 & 30 & 5 & 2,2 & 2,6 & 2,4 & 4 & 4 & 4 \\
\hline 21 & 15840 & 15360 & - & 40 & 43 & - & 2,2 & 2,6 & 2,4 & 4 & 4 & 4 \\
\hline 22 & 2430 & 2500 & 10 & 25 & 25 & 20 & 2,4 & 2,4 & 2,6 & 4 & 4 & 4 \\
\hline 23 & 2405 & 1225 & 5 & 5 & 30 & 40 & 1,8 & 2,0 & 2,0 & 4 & 4 & 4 \\
\hline 24 & 880 & 720 & 5 & 50 & 20 & 20 & 2,0 & 2,2 & 2,0 & 4 & 4 & 4 \\
\hline 25 & 75 & 65 & - & 30 & 20 & 10 & 2,2 & 2,2 & 2,0 & 4 & 4 & 4 \\
\hline
\end{tabular}

* Em ordem crescente de qualidade, onde: 4- Coágulo "bom"; 3- Coágulo "regular"; 2- Coágulo "deficiente"; 1- Coágulo "muito deficiente".

Tabela 2 - Valores da \% média obtidos na análise citológica do líquido sinovial de eqüinos analisado a fresco (GI), após refrigeração (GII) e congelamento (GIII).

\begin{tabular}{cccc}
\hline Célula & GI & GII & GIII \\
\hline & & & \\
Linfócito & 78,36 & 83,68 & 70,12 \\
Monócito & 16,16 & 11,92 & 20,68 \\
Neutrófilo & 4,8 & 4,0 & 1,2 \\
Eosinófilo & 0,2 & 0,4 & - \\
& & & \\
\hline
\end{tabular}

conseqüentemente, da articulação (SPIERS et $\boldsymbol{a l}$., 1994).

A contagem total de eritrócitos revelou diferença significativa entre os três grupos $(p<0,05)$, o que comprovou a fragilidade dos eritrócitos quando sob refrigeração e congelamento. DUNCAN \& PRASSE (1986) citaram que a presença de eritrócitos deve ser rara no líquido sinovial normal, o que não foi observado no Grupo GI (Tabela 1), no qual o menor valor observado foi de 60 eritrócitos $/ \mathrm{mm}^{3}$ e o maior de $15850 / \mathrm{mm}^{3}$. Tais achados podem estar relacionados à contaminação por sangue proveniente da técnica percutânea utilizada (MISHEFF \& STOVER, 1991). Nesses casos de contaminação, há um aumento de leucócitos proporcional ao aumento de eritrócitos, o que não foi observado neste experimento. A razão eritrócito: leucócito foi muito variável. Considera-se que a redução do número de eritrócitos não altera, de modo drástico, a fisiologia do líquido sinovial desde que se encontre dentro dos valores de normalidade.

Quanto ao teste de precipitação de mucina, todos os grupos se mostraram equivalentes $(\mathrm{p}>0,05)$. A mucina mostrou estabilidade satisfatória durante o experimento, o que foi notado em líquidos sinoviais que apresentaram coágulos de mucina "bons" no GI. Já os coágulos de mucina "regulares" (GI) não se mantiveram estáveis após refrigeração e congelamento (GII e GIII), ou seja, o coágulo de mucina só se mantém estável após refrigeração e congelamento, se for classificado como coágulo “bom”, a fresco.

Houve predomínio de linfócitos na análise citológica (Tabela 2), o que diferencia dos achados de MAHAFFEY (1992), que cita os monóci- 
tos/macrófagos como sendo as células de predomínio no líquido sinovial. Eosinófilos foram encontrados em aproximadamente 2,7\% das análises. Em 96\% das análises realizadas nesse experimento, os neutrófilos não excederam $10 \%$, o que corrobora os achados de MAHAFFEY (1992). Também foram encontradas alterações morfológicas em $8 \%$ das análises do GII e em $64 \%$ das GIII.

\section{CONCLUSÕES}

Nas condições deste experimento, pode-se concluir que o líquido sinovial sofre alterações quanto à proteína e celularidade após refrigeração e congelamento, porém ainda se mantendo dentro dos parâmetros de normalidade citados pela literatura. O coágulo de mucina a fresco, considerado "bom", não apresenta alteração após refrigeração e congelamento. $\mathrm{O}$ congelamento proporciona menos alterações que a refrigeração, sendo, portanto, melhor.

\section{AGRADECIMENTOS}

A Fernando Bonna pelo apoio e companheirismo. A Rogéria Serakides e Renato Lima Santos pela gentileza de ajudar com as fotografias. A Danilo pela colaboração com a estatística. A Iuri e Prof. Marc Henry pelos animais cedidos ao experimento. A todos aqueles que direta, ou indiretamente, contribuíram para este trabalho.

\section{REFERÊNCIAS BIBLIOGRÁFICAS}

ARMITAGE, P. Statistical methods in medical research, London: Blackwell Scientific Publications, 1971, 504 p.

CLYNE, M. J. Pathogenesis of degenerative joint disease. Equine
Vet J, v. 19, n. 1, p. 15-18, 1987.

DUNCAN, J.R., PRASSE, K.W. Veterinary laboratory medicine: clinical pathology, 2. ed. Ames: Iowa State University Press, p. 212-14,1986.

GIBSON, K.T., HODGE, H., WHITTEM, T. Inflamatory mediators in equine synovial fluid. Austral Equine Vet, v. 73, n. 4, p. 148-151, 1996.

MAHAFFEY, E.A. Synovial fluid. In: COWELL, R.L., TYLER, R.D. (Ed.). Cytology and hematology of the horse. Philadelphia: Mosby, 1992. p. 153-161.

MENDE, G.A.G. Allotransplantation of synovial fluid in equine species as a therapeutic alternative in some arthropathies and synovial effusions. Equine Prac, v. 10, n.7, p. 27-30, 1988.

MISHEFF, M. M., STOVER, S. M. A comparison of two techniques for arthrocentesis of the equine metacarpophalangeal joint. Equine Vet J, v. 23, n. 4, p.273-76, 1991.

SPIERS, S., MAY, S.A., BENNETT, D., et al. Cellular sources of proteolytic enzymes in equine joints. Equine Vet J, v. 26, n. 1, p. $43-50,1994$.

STASHAK, T. S. Adams lamenesses in horses, 4. ed. Philadelphia: Lea \& Febiger, 1987, 906 p.

STONEHAM, S.J. Septic arthritis in foal: practical considerations on diagnosis and treatment. Equine Vet Educ, v. 9, n. 1, p. 2529, 1997.

WELCH, R.D., DeBOWES, R.M., LIEPOLD, H.W. Evaluation of the effects of intra-articular injection of dimethylsulfoxide on normal equine articular tissues. Am J Vet Res, v. 50, n. 7, p. 1180-82, 1989

YANCIK, S.A., McILWRAITH, C.W., WAGNER, A.E., $\boldsymbol{e} \boldsymbol{t}$ al. Evaluation of creatine kinase and lactate dehydrogenase activities in clinically normal and abnormal equine joints. Am J Vet Res, v. 48, n.3, p. 463-66, 1987.

Ciência Rural, v. 29, n. 1, 1999. 